\title{
Corrigendum: Anxiety and Depression Among People Under the Nationwide Partial Lockdown in Vietnam
}

\author{
Huong Thi Le ${ }^{1}$, Andre Jun Xian Lai ${ }^{2}$, Jiaqian Sun ${ }^{2}$, Men Thi Hoang ${ }^{3,4 *}$, Linh Gia Vu ${ }^{5}$, \\ Hai Quang Pham ${ }^{3,4}$, Trang Ha Nguyen ${ }^{3,4}$, Bach Xuan Tran ${ }^{1,6}$, Carl A. Latkin ${ }^{6}$, \\ Xuan Thi Thanh Le ${ }^{1}$, Thao Thanh Nguyen ${ }^{1}$, Quan Thi Pham ${ }^{1}$, Nhung Thi Kim Ta ${ }^{1}$, \\ Quynh Thi Nguyen ${ }^{1}$, Roger C. M. Ho ${ }^{2,7}$ and Cyrus S. H. Ho ${ }^{8}$
}

\begin{abstract}
${ }^{1}$ Institute for Preventive Medicine and Public Health, Hanoi Medical University, Hanoi, Vietnam, ${ }^{2}$ Department of Psychological Medicine, Yong Loo Lin School of Medicine, National University of Singapore, Singapore, Singapore, ${ }^{3}$ Institute for Global Health Innovations, Duy Tan University, Da Nang, Vietnam, ${ }^{4}$ Faculty of Medicine, Duy Tan University, Da Nang, Vietnam, ${ }^{5}$ Center of Excellence in Evidence-based Medicine, Nguyen Tat Thanh University, Ho Chi Minh City, Vietnam, ${ }^{6}$ Bloomberg School of Public Health, John Hopkins University, Baltimore, MD, United States, ${ }^{7}$ Institute for Health Innovation and Technology (iHealthtech), National University of Singapore, Singapore, Singapore, ${ }^{8}$ Department of Psychological Medicine, National University Hospital, Singapore, Singapore
\end{abstract}

Keywords: COVID-19, anxiety, depression, lockdown, Vietnam

\section{A Corrigendum on}

Anxiety and Depression Among People Under the Nationwide Partial Lockdown in Vietnam by Le, H. T., Lai, A. J. X., Sun, J., Hoang, M. T., Vu, L. G., Pham, H. Q., et al. (2020). Front. Public Health 8:589359. doi: 10.3389/fpubh.2020.589359

\section{Edited and reviewed by:} Wulf Rössler,

Charité - Universitätsmedizin Berlin, Germany

*Correspondence: Men Thi Hoang hoangthimen@duytan.edu.vn

Specialty section:

This article was submitted to Public Mental Health,

a section of the journal

Frontiers in Public Health

Received: 07 April 2021 Accepted: 14 April 2021 Published: 24 May 2021

Citation:

Le HT, Lai AJX, Sun J, Hoang MT,

Vu LG, Pham HQ, Nguyen TH,

Tran BX, Latkin CA, Le XTT,

Nguyen TT, Pham QT, Ta NTK,

Nguyen QT, Ho RCM and Ho CSH (2021) Corrigendum: Anxiety and Depression Among People Under the Nationwide Partial Lockdown

Front. Public Health 9:692085. doi: 10.3389/fpubh.2021.692085
In the original article, there was a mistake in Table $\mathbf{1}$ as published. The corresponding author uploaded an incorrect table that did not match the relevant text in the result section. The corrected Table 1 appears below. uploaded an incorrect table that did not match the relevant text in the result section. The corrected Table 2 appears below.

In the original article, there was a mistake in Table 3 as published. The corresponding author uploaded an incorrect table that did not match the relevant text in the result section. The corrected Table 3 appears below.

In the original article, there was a mistake in Table 4 as published. The corresponding author uploaded an incorrect table that did not match the relevant text in the result section. The corrected Table 4 appears below.

In the original article, there was an error.

A correction has been made to 3. Results, 3.1. Tables, Paragraph 03, line 131 and Paragraph

"Table 3 shows the mental well-being of respondents during COVID-19. Based on DASS 21 scale scoring, $4.9 \%$ of respondents were classified as having moderate to extremely severe levels of depression, $7.0 \%$ of respondents had moderate to extremely severe levels of anxiety, and $3.4 \%$ of respondents scored moderate to extremely severe levels of stress. Mean scores for depression, anxiety, and stress were $2.7(\mathrm{SD}=6.5), 2.4(\mathrm{SD}=6.3)$, and $4.7(\mathrm{SD}=7.0)$, respectively".

"Table 4 shows the factor associated with the depression, anxiety, and stress related to COVID-19. Married respondents had lower depression, anxiety, and stress levels than those that were single, separated, or widowed. Participants who are postgraduates had significantly higher stress levels than those with education level of high school and below $(p<0.05)$.
In the original article, there was a mistake in Table 2 as published. The corresponding author 04, line 139: 
A larger family size of more than 5 people was also linked to higher levels of depression, anxiety, and stress $(p<0.1)$ than those with family size of 1-2 people".

The authors apologize for this error and state that this does not change the scientific conclusions of the article in any way. The original article has been updated.
Copyright $\odot 2021$ Le, Lai, Sun, Hoang, Vu, Pham, Nguyen, Tran, Latkin, Le, Nguyen, Pham, Ta, Nguyen, Ho and Ho. This is an open-access article distributed under the terms of the Creative Commons Attribution License (CC BY). The use, distribution or reproduction in other forums is permitted, provided the original author $(s)$ and the copyright owner(s) are credited and that the original publication in this journal is cited, in accordance with accepted academic practice. No use, distribution or reproduction is permitted which does not comply with these terms.

TABLE 1 | Socioeconomics characteristics of participants.

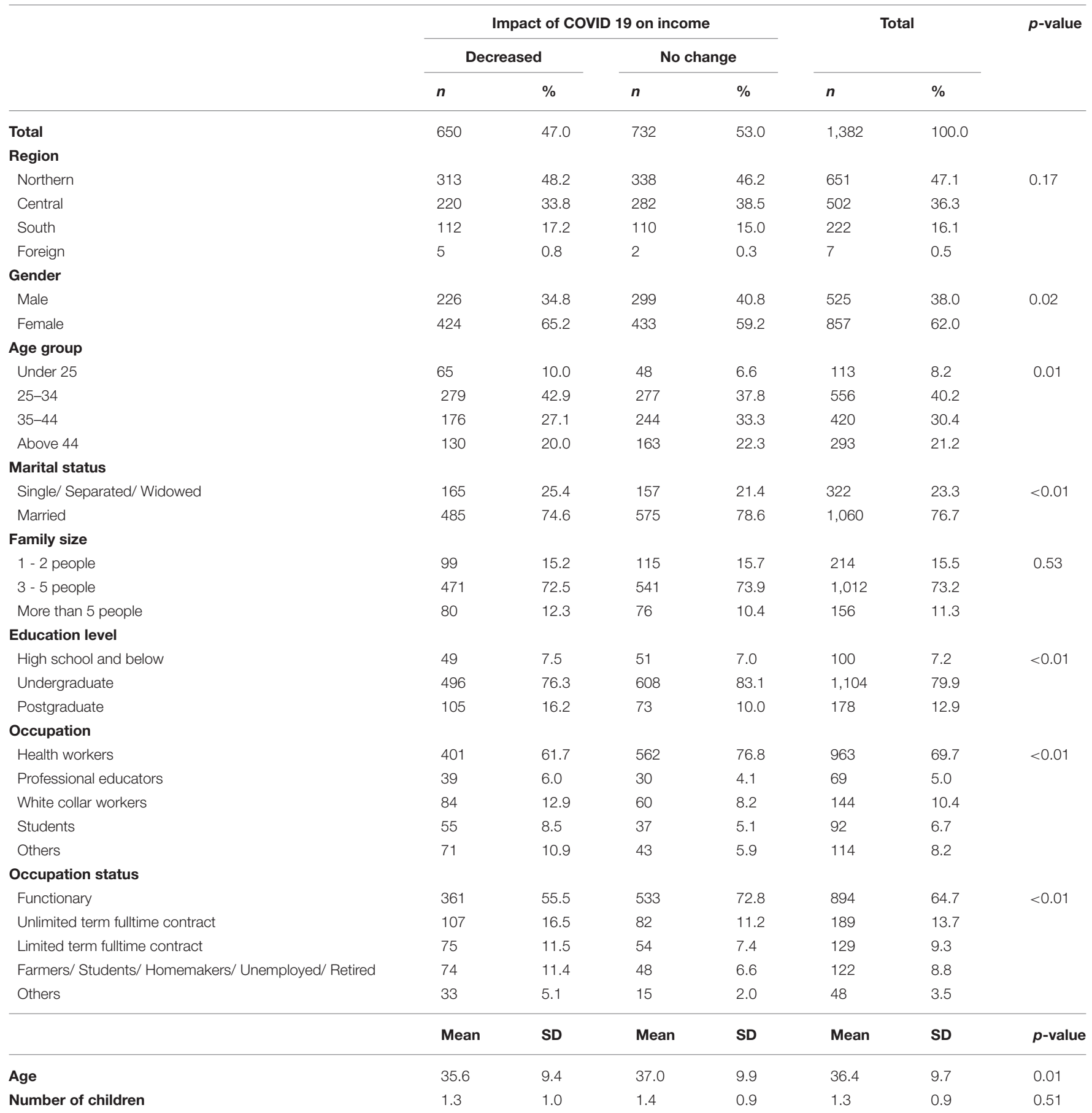


TABLE 2 | Impact of COVID-19 on participant life.

\begin{tabular}{|c|c|c|}
\hline & \multicolumn{2}{|c|}{ Total } \\
\hline & $n$ & $\%$ \\
\hline Had outpatient examination in last 14 days & 74 & 5.4 \\
\hline Had COVID-19 test in last 14 days & 37 & 2.7 \\
\hline Been isolated in last 14 days & 51 & 3.7 \\
\hline Have health insurance & 1,356 & 98.2 \\
\hline \multicolumn{3}{|l|}{ COVID 19 impact on occupation status } \\
\hline No effect & 602 & 43.6 \\
\hline Fired & 39 & 2.8 \\
\hline Reduced working hours/shift & 217 & 15.7 \\
\hline Have to work overtime & 524 & 37.9 \\
\hline \multicolumn{3}{|l|}{ Amount of income effected by COVID-19 } \\
\hline Increased 80-100\% & 1 & 0.1 \\
\hline Increased 60-80\% & 0 & 0.0 \\
\hline Increased 40-60\% & 1 & 0.1 \\
\hline Increased 20-40\% & 3 & 0.2 \\
\hline Increased $<20 \%$ & 3 & 0.2 \\
\hline No change & 724 & 52.4 \\
\hline Decreased $<20 \%$ & 202 & 14.6 \\
\hline Decreased 20-40\% & 189 & 13.7 \\
\hline Decreased 40-60\% & 168 & 12.2 \\
\hline Decreased 60-80\% & 56 & 4.1 \\
\hline Decreased 80-100\% & 35 & 2.5 \\
\hline \multicolumn{3}{|l|}{ History of contact to COVID-19 } \\
\hline Close contact with COVID-19 infected person & 25 & 1.8 \\
\hline $\begin{array}{l}\text { Contact with people who have directly exposed to } \\
\text { COVID-19 patient }\end{array}$ & 100 & 7.2 \\
\hline Contact with suspected COVID-19 infected people & 186 & 13.5 \\
\hline $\begin{array}{l}\text { Contact with objects which possibility contain the COVID-19 } \\
\text { virus }\end{array}$ & 55 & 4.0 \\
\hline Never had contact with COVID-19 infected person & 1,099 & 79.5 \\
\hline
\end{tabular}


TABLE 3 | Mental well-being of respondents during COVID-19.

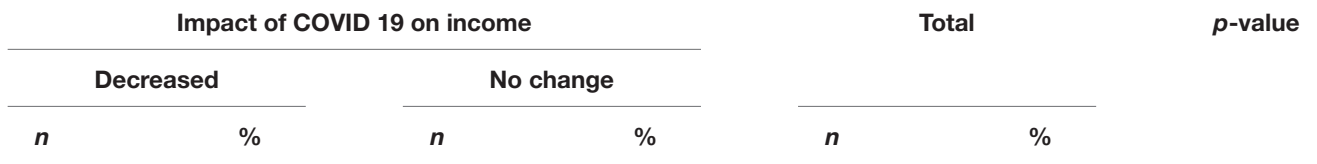

\section{Depression}

Normal

Mild

Moderate

Severe

Extremely severe

\section{Anxiety}

Normal

Mild

Moderate

Severe

Extremely severe

Stress

Normal

Mild

Moderate

Severe

Extremely severe

IES-R score interpretation

Not concerned at all

Rarely concerned

Concerned

Extremely concerned

\section{6}

36

21

2

15

584

14

34

3

15

607

19

8

6

10

449

100

46

55

\section{6}

5.5

3.2

0.3

2.3

89.8

2.2

5.2

0.5

2.3

93.4

2.9

1.2

0.9

1.5

69.1

15.4

7.1

8.5
94.0

1.8

1.9

0.1

2.2

92.6

1.4

3.1

0.3

2.6

95.8

1.1

0.7

0.3

2.2

79.0

12.7

3.0

5.3
1,264

49

35

3

31

1,262

24

57

5

34

1,308

27

13

8

26

1,027

193

68

94
91.5

3.5

2.5

0.2

2.2

1.7

4.1

0.4

2.5

Mean

SD

Mean

SD

Mean

5.8
5.5
6.5
13.3

2.7

2.4

4.7

16.3

2.4
2.1
4.6
16.3

5.5

13.3
13.4

94.6

2.0

0.9

0.6

1.9

$<0.01$

IES-R score (band score: 0-88)

16.5

74.3

14.0

4.9

6.8

SD

p-value

Depression (band score: 0-42)

$\begin{array}{ll}3.2 & 7.6 \\ 2.8 & 7.4 \\ 4.9 & 7.7 \\ 16.5 & 13.4\end{array}$

$\begin{array}{lll}2.7 & 6.5 & 0.27 \\ 2.4 & 6.3 & 0.92 \\ 4.7 & 7.0 & 0.78 \\ 16.3 & 13.3 & 0.76\end{array}$


TABLE 4 | Associated factors with depression, anxiety and stress related to COVID 19 among Vietnamese.

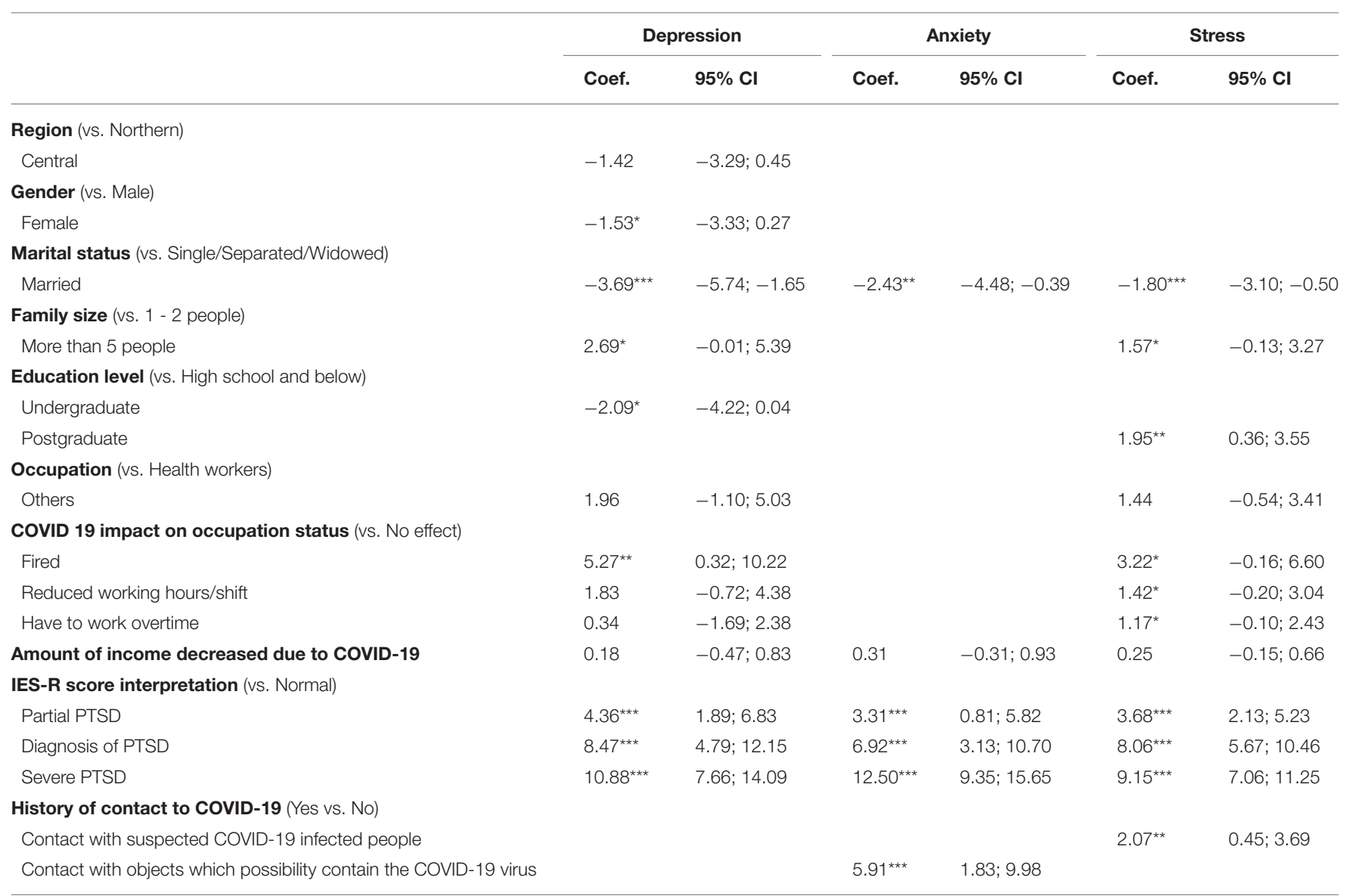

${ }^{\star * *} p<0.01,{ }^{* *} p<0.05,{ }^{*} p<0.1$. 